\title{
Response analysis and vibroinsulation of buildings subject to technical seismicity
}

\author{
D. Makovička ${ }^{1} \&$ D. Makovička Jr. ${ }^{2}$ \\ ${ }^{1}$ Czech Technical University in Prague, \\ Klokner Institute, Czech Republic \\ ${ }^{2}$ Static and Dynamic Consulting, Czech Republic
}

\begin{abstract}
Building structures in the vicinity of transport lines are loaded by vibrations excited by the passage of motor vehicles or trains. These vibrations propagate as technical seismicity effects through the soil to the foundations of buildings in the vicinity of their source. Due to its tuning, the building structure usually amplifies or, in better cases, reduces the effects of technical seismicity. An effective method for reducing the vibration level of the protected structure as a whole with reference to its foundation structures (plate, piles, strips, etc.) is to spring it from the foundations. This springing is usually effected by placing the whole upper part of the structure on individual springs or sprung layers. The effectiveness of the springing is determined by the frequency tuning of the sprung structure. This paper deals with the application of an elastic antivibration layer at the foundation base level in order to eliminate excessive vibrations propagating to the assessed building through the geological environment as technical seismicity.
\end{abstract}

Keywords: building structure, transport effects, vibroprotection, dynamic response.

\section{Introduction}

The dynamic effects of subsurface traffic propagating through the ground environment into the ambient buildings of urban agglomerations have been acquiring ever-increasing importance. Construction firms make efforts to exploit areas in the proximity of underground lines because of their lucrative location, usually for residential construction. In the proximity of underground tunnels or 
directly above shallow tunnels they erect structures that are threatened by vibrations from underground traffic.

Trains running through underground tunnels produce vibrations (Figure 1), which, together with the vibrations from a wide range of constituents of the underground railway, such as ventilation fans and escalator drives, propagate from the source to more distant structures. As a rule, these vibrations propagate into the building foundations at the foundations/subgrade interface. Vibrations produced by subsurface traffic usually do not threaten the safety of structures. Nevertheless, they may be significant because of their undesirable impacts on people living or working in the residential or office parts of the building, especially due to their tuning.

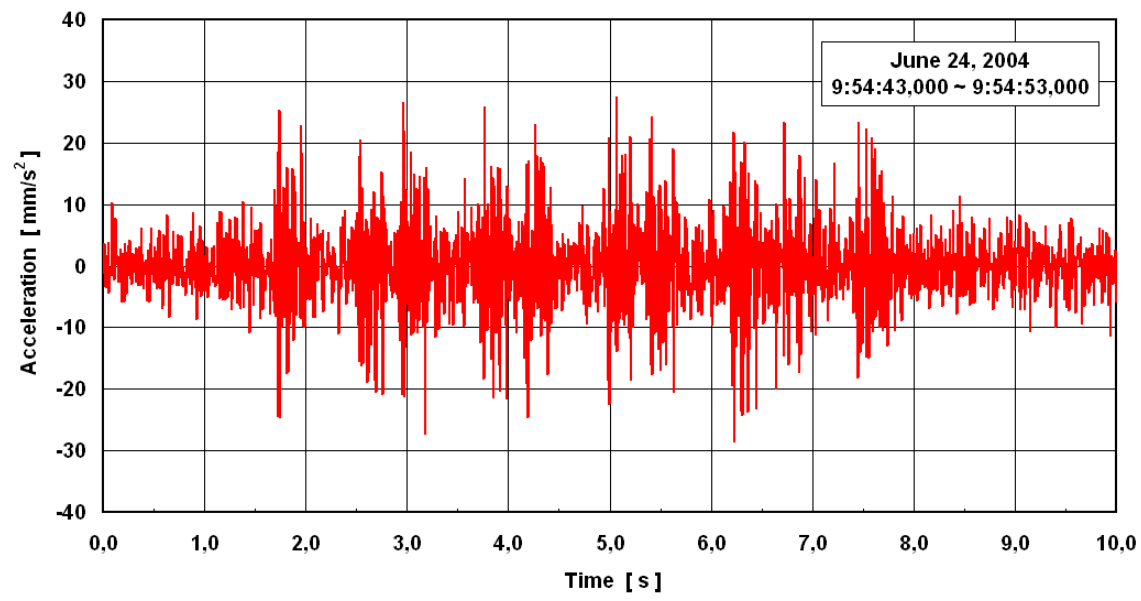

Figure 1: $\quad$ Measured time history of vertical vibration excited by a passing train.

The magnitude of the vibrations is influenced not only by the vibration parameters at the source, but also by the composition of the geological environment in the proximity of the underground railway, i.e. the route from the source to the threatened structure. Last but not least, the magnitude of these vibrations may be increased or damped by the actual execution of the structure loaded by them.

When planning the correct measures for a structure that we intend to protect against excessive vibrations, we therefore need to know the amplitude level and the frequency structure of the vibrations that will propagate from the underground into the building (Figure 2).

However, the measured real characteristics of the vibrations may show considerable mutual differences (Figure 3), because the magnitude of the vibrations $\left(a_{\mathrm{ef}}\right)$ and their frequency structure depend not only on the general parameters (train design, permanent way, structures of stations and tunnels, etc.) but also on local parameters on the site (particularly the composition of the geological environment, foundation design, etc.) 


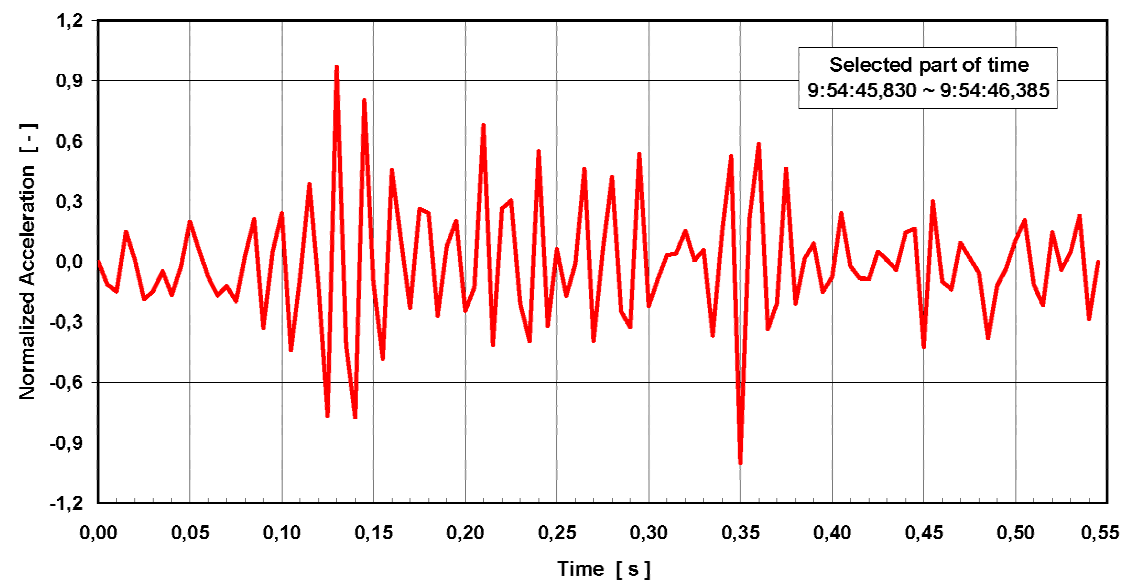

Figure 2: $\quad$ Selected part of the time history of vertical vibration as input data for vibration analysis.

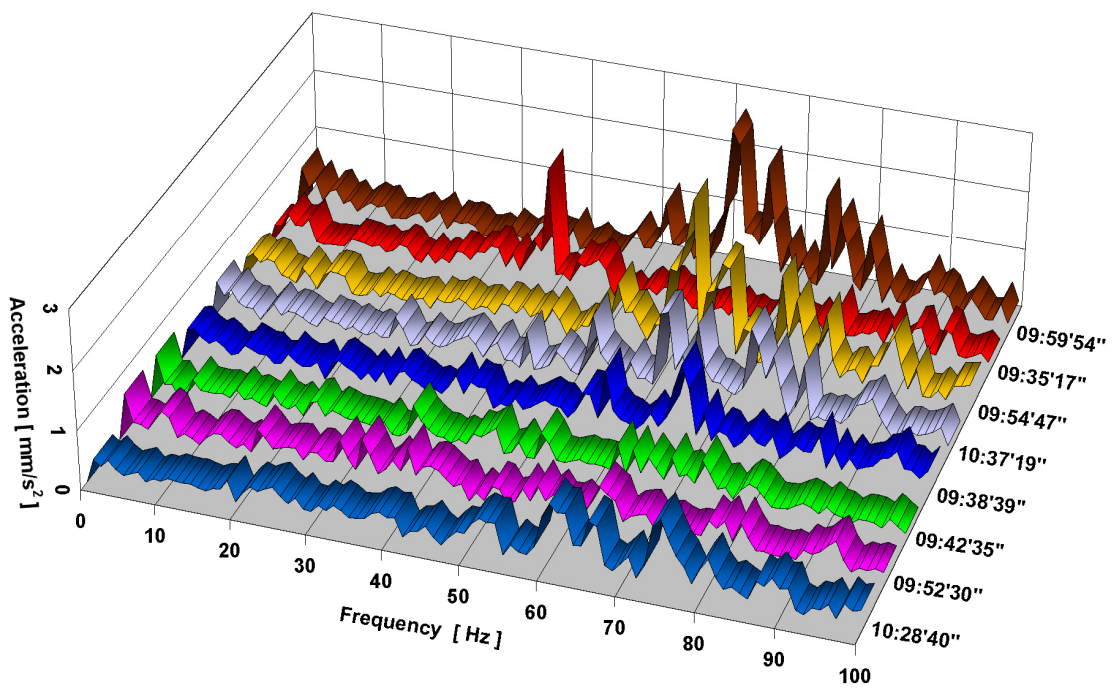

Figure 3: $\quad$ FFT spectra of vertical vibration as trains pass.

Therefore, a responsible designer of measures for reducing vibration transfer into the structure to be protected needs, first of all, to perform vibration measurements on site, and to evaluate them, preferably at the foundation base level. These measurements produce typical histories of vibrations affecting selected parts of the structure, which can be considered as the dynamic load of the future or existing structure at its foundation level. This vibration load has a non-stationary character. 


\section{Elastic support for the structure at its foundation level}

An effective method for reducing the vibration level of the protected structure as a whole with reference to its foundation structures (plate, strips, etc.) is to spring it from the foundations. This springing is usually effected by placing the whole upper part of the structure on individual springs or sprung layers.

The effectiveness of the springing is determined by the frequency tuning of the sprung structure. The lower the tuning of the structure based on springs (the lower the dominant natural frequencies), the greater the decrease in the higher vibration frequencies and acoustic frequency effects propagating into the structure from its geological environment.

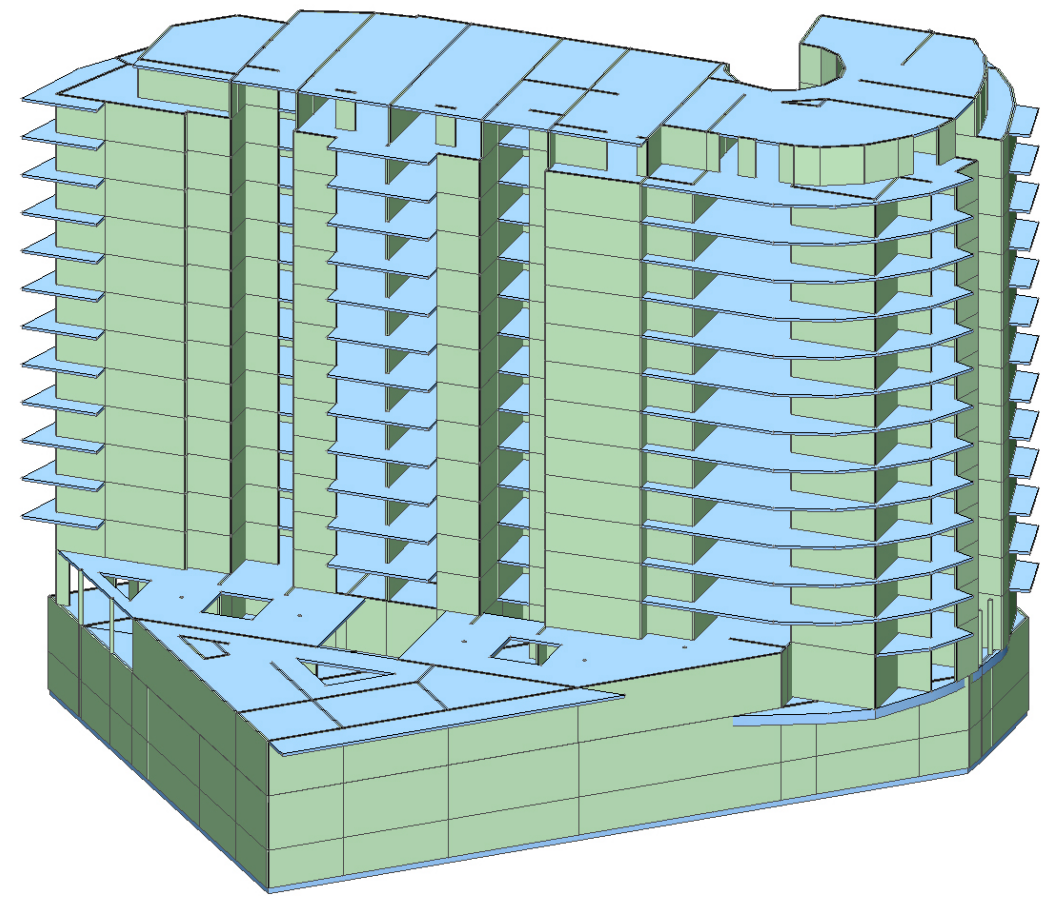

Figure 4: Calculation model.

The solution of vibration transfer from the subsoil environment to the building structure is demonstrated using the example of a multi-storey reinforced concrete building, founded on large diameter piles mutually connected with the lower foundation plate by reinforcement. On top of this plate an antivibration layer of rubber has been designed. Above the rubber there is an upper foundation plate in which the cast-in-place skeleton building structure is constrained.

Consequently, the elastic layer of rubber consistently separates the lower and upper parts of the foundation plate and the lower and upper parts of the self- 
supporting footings (horizontal layers of rubber), as well as all vertical structural members below ground level, from the ambient environment (vertical, slanting and horizontal layers of rubber surrounding the columns in the soil, outside walls below ground level, the upper part of footings or foundation strips in contact with the soil backfill).

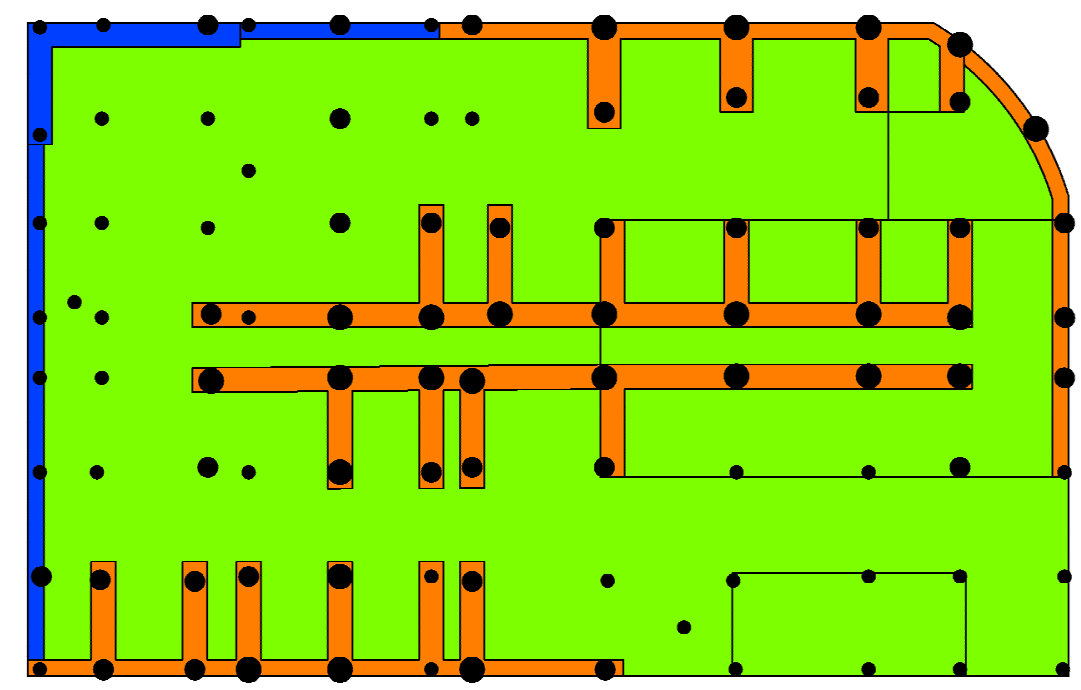

Figure 5: Vibrobase insulation - distribution of various types of rubber.

A numerical model of the building (Figure 4), together with the lay-out of the rubber distribution in the foundation part (Figure 5), takes into account the individual storeys, broken down into the floor, foundation and roof slabs, columns, load-bearing walls and peripheral and interior girders.

The layer of rubber was considered as the elastic subsoil of the WinklerPasternak model below the whole area of the upper part of the foundation plate, and as the elastic support for columns and walls above the piles on the upper foundation plate level. The stiffness of the rubber in the theoretical model takes into account the type of plates used as well as the mutual superposition of surface and point support on the upper foundation plate level. The mass of the floor and foundation plates includes the masses of the non-load-bearing components (thin partitions, floorings, etc.) as well as the equivalent of the useful loads of the floors, roof and terraces.

The mechanical characteristics of the antivibration rubber layer were determined by laboratory tests on $500 \times 500 \times 25 \mathrm{~mm}$ samples that were used to form the vibration-resistant layer. The rubber blocks (slabs) are butt-jointed (not interlocked) in a single layer with $3 \sim 5 \mathrm{~mm}$ joints enabling the rubber to buckle, thus assuring identical conditions of deformability and, consequently, stiffness corresponding to the conditions at the foundation base. 
Table 1: $\quad$ The lowest natural frequencies and modes.

\begin{tabular}{|c|c|}
\hline $\begin{array}{l}\text { Natural } \\
\text { frequency }\end{array}$ & Character of natural mode \\
\hline $1,99 \mathrm{~Hz}$ & $\begin{array}{l}\text { Translation and rotation of above-ground part of building } \\
\text { in SW direction }\end{array}$ \\
\hline $2,58 \mathrm{~Hz}$ & Rotation of whole building round the $z$ axis \\
\hline $2,66 \mathrm{~Hz}$ & $\begin{array}{l}\text { Translation and rotation of above-ground part of building } \\
\text { in } \mathrm{S} \text { direction }\end{array}$ \\
\hline $5,75 \mathrm{~Hz}$ & Local vibration of parts of floor slabs \\
\hline $5,79 \mathrm{~Hz}$ & $\begin{array}{l}\text { Translation and rotation of above-ground part of building } \\
\text { in NE direction }\end{array}$ \\
\hline 5,92 & Rotation of above-ground part of building round the $z$ axis \\
\hline
\end{tabular}

\section{Prediction of vibro-based structure response}

The natural vibrations were computed for the analyzed building structure. For the dynamic response to the effects of external actions (traffic), the lowest possible tuning of the rubber-mounted structure is decisive. This manifests itself, on the one hand, by flexural vibrations of the vibro-based building in the environs of $1 \mathrm{~Hz}$, and, on the other hand, by vertical and horizontal translate vibrations of the building as a whole or by torsion vibrations. The lowest six vibration modes are shown in Table 1.

Not only the basic natural vibration modes but also the higher natural vibration frequencies of the individual storeys, possibly columns and walls, balconies, etc., appear in the computation, which makes the response of the building on each storey slightly different (higher, lower, possibly with antinodes on different sites).

Vibrations of the building produced by underground traffic were determined by the histories of the forced vibrations. In addition, the envelopes of the maximum values of the transient vibrations in the displacements were evaluated and documented for selected under-ground and above-ground storeys in Figure 6 and Figure 7.

The history of the kinematic excitation is shown in Figure 6 in normalized form. Its maximum amplitude is equal to one. The history of the response displacement in this figure was also normalized, but to the maximum of the displacement of the baseplate under first under-ground storey, where the seismic load acts. Thus, if the response displacement is smaller than dimensionless value one, the vibration in this location of a storey is smaller than the vibration of the maximally vibrated point of the baseplate; and if it is the other way round (if the value is greater than one) the vibration is amplified. This figure can be used to compare the effectiveness of the vibroinsulation of the building. 


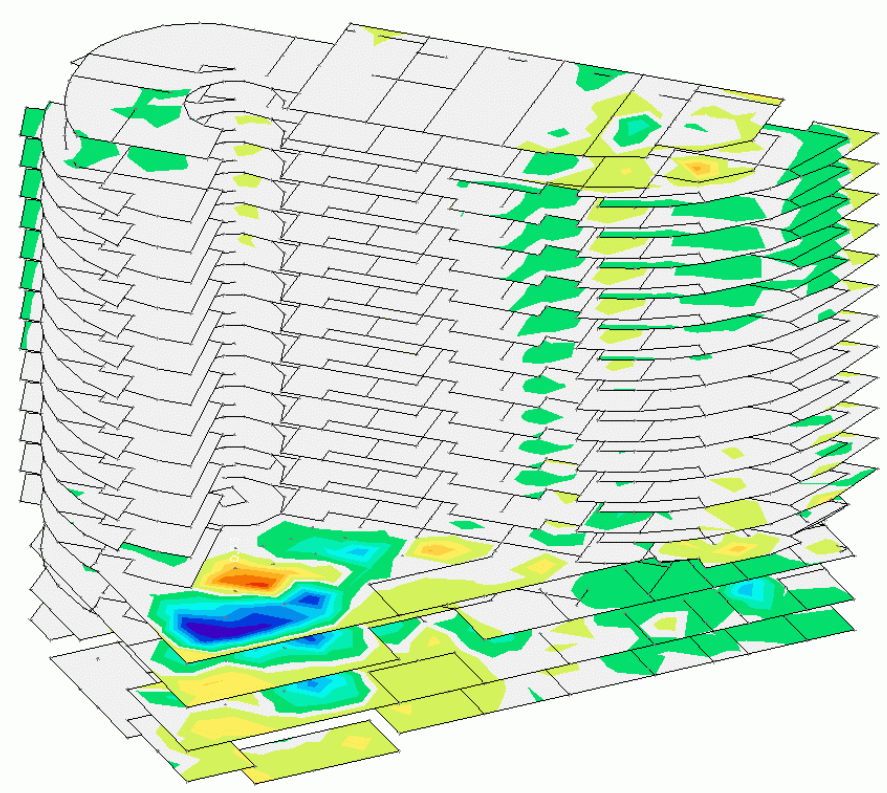

Figure 6: Vertical vibration of the whole building in the time step $0.19 \mathrm{~s}$.

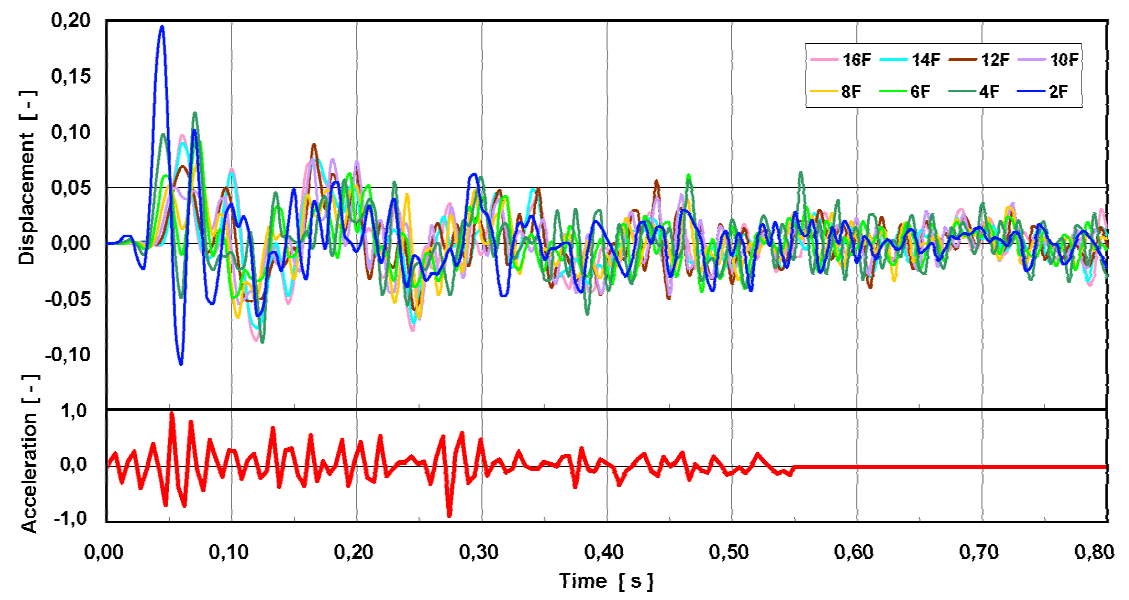

Figure 7: Maximum normalized vertical displacements of selected storeys in relation to excitation.

The computed vibration histories reveal that the vibrations due to underground train traffic introduced into the structure are felt particularly in the lowest storey (Figure 6). The most intensive vibrations can be observed in the proximity of columns and structural parts situated on the underground side. With 
increasing height, this excitation mode will manifest itself by vibrations of the building in one of the natural frequencies of the structure.

More significant influence of vibration is limited to the lowest two or three storeys, in most cases. In the higher storeys, the time characteristic of the vibrations is divided into lower frequencies. Other elements reducing the vibration level in the individual storeys are the non-load-bearing partitions, floating floors, carpet floorings, etc.; an analysis of these factors, however, is beyond the range of this paper.

The response computation during vertical versus horizontal excitation reveals that the horizontal excitation level is lower than the vertical excitation level according to the measurements, approximately twice as low. Moreover, the response to horizontal excitation is of very low frequency, as a rule, and it is also damped faster than in the case of vertical excitation.

\section{Conclusion}

This paper deals with the application of an elastic antivibration layer at the foundation base level in order to eliminate excessive vibrations propagating to the assessed building through the geological environment from an underground railway structure. When a train is in motion, the dominant vibrations are transferred to the environs in the form of non-stationary vibrations produced by the motion of the train across the interface of the different types of underground tunnel structures (in our case).

Measurements at the baseplate ascertained vibrations exceeding the permissible limit for human comfort. This was the main reason for springing the whole building structure. The histories of the measured vibrations were used as loads applied to a modelled building structure at the foundation base of which a separating elastic rubber layer had been designed. For such a model, the predicted vibrations in the individual storeys were shown and were compared with the level of excitation vibrations on the foundation base. In the case of hard inelastic placing of the building on piles without springing, the vibrations would propagate from the subgrade directly into the $\mathrm{RC}$ building structure, practically without decreasing. The application of springing is, consequently, a very efficient instrument for reducing the transfer of vibration from the subgrade to the interior parts of the building.

\section{Acknowledgement}

This research was supported as a part of the research projects in GAČR 103/08/0859 "Structure response under static and dynamic loads caused by natural and man induced activity", for which the authors would like to thank the Agency.

\section{References}

[1] Booth, E: Seismic design practice into the next century. A. A. Balkema, Rotterdam, 1998. 
[2] Makovička, D. \& Makovička, D.: The use of ductility reserves of structure bearing capacity in seismic analysis. Engineering Mechanics, Inst. of Thermomechanics, Ac. of Sci. of CR, Prague, pp. 211-212 + 9 pp on CD, 2005.

[3] Makovička, D. \& Makovička, D.: Determination of seismic transport effects on buildings, In: Brebbia, C.A.: Earthquake Resistant Engineering Structures VI, WIT Press, Southampton, pp. 353-362, 2007.

[4] Makovička, D. \& Makovička, D.: Principle of the dynamic filter for the reduction of vibration transfer from the subsoil to the structure (in Czech), Stavební obzor, No.5, pp. 129-133, 2008. 